\title{
REVIEW
}

\section{Exercise training in COPD patients: the basic questions}

\author{
R. Gosselink, T. Troosters, M. Decramer
}

Exercise training in COPD patients: the basic questions. R. Gosselink, T. Troosters, M. Decramer. (CERS Journals Ltd 1997.

ABSTRACT: Pulmonary rehabilitation programmes aim at improving exercise capacity, activities of daily living, quality of life and perhaps survival in patients with chronic obstructive pulmonary disease (COPD). Recently, well-designed studies investigated and confirmed the efficacy of comprehensive pulmonary rehabilitation programmes, including exercise training, breathing exercises, optimal medical treatment, psychosocial support and health education. In the present overview, the contribution of exercise training in clinical practice to the demonstrated effects of pulmonary rehabilitation is discussed by means of six basic questions. These include: 1) the significance of exercise training; 2) the optimal intensity for exercise training; 3) prescribing training modalities; 4) the effects of exercise training combined with medication, nutrition or oxygen; 5) how training effects should be maintained; and 6 ) where the rehabilitation programme should be performed: in-patient, out-patient or homecare?

First, exercise training has been proven to be an essential component of pulmonary rehabilitation. Training intensity is of key importance. High-intensity training ( $>70 \%$ maximal workload) is feasible even in patients with more advanced COPD. In addition, the effects on peripheral muscle function and ventilatory adaptations are superior to low-intensity training. There is, however, no consensus on the optimal training modalities. Both walking and cycling improved exercise performance. Since peripheral muscle function has been recognized as an important contributor to exercise performance, specific peripheral muscle training recently gained interest. Improved submaximal exercise performance and increased quality of life were found after muscle training. The optimal training regimen (strength or endurance) and the muscle groups to be trained, remain to be determined. Training of respiratory muscles is recommended in patients with ventilatory limitation during exercise. The additional effects of anabolic-androgenic drugs, oxygen and nutrition are not well-established in COPD patients and need further research.

In order to maintain training effects, close attention of the rehabilitation team is required. The continuous training frequency necessary to maintain training effects remains to be defined.

At this point in time, out-patient-based programmes show the best results and guarantee the best supervision and a multidisciplinairy approach. Future research should focus on the role of homecare programmes to maintain improvements.

Eur Respir J, 1997; 10: 2884-2891.
Respiratory Rehabilitation and Respiratory Division, University Hospitals, Katholieke Universiteit Leuven, B-3000 Leuven, Belgium, and Faculty of Physical Education and Physiotherapy, Katholieke Universiteit Leuven, B-3000, Belgium

Correspondence: R. Gosselink

Division of Respiratory Rehabilitation

University Hospital Gasthuisberg

Herestraat 49

3000 Leuven

Belgium

Keywords: Chronic obstructive pulmonary disease

exercise training

rehabilitation

Received: April 291997

Accepted after revision July 101997

Supported by the 'Fonds voor Wetenschappelijk Onderzoek - Vlaanderen' grant No. 3.0167.95 and grant No. P. 0188.97.
Dyspnoea, impaired exercise tolerance and reduced quality of life are common complaints in patients with chronic obstructive pulmonary disease (COPD). Several pieces of evidence point to the fact that these features are not simple consequences of the loss of pulmonary function. Reduced exercise capacity shows only a weak relation to lung function impairment [1]. Moreover, medication may improve pulmonary function in COPD, but does not necessarily have a clear effect on exercise capacity [2]. Other factors, such as peripheral muscle weakness, deconditioning and impaired gas exchange, are now recognized as important contributors to reduced exercise tolerance $[3,4]$.

The consequences of exercise intolerance appear important to COPD patients. Reduced exercise capacity and muscle weakness render these patients disabled with a high utilization of healthcare resources $[5,6]$. They refrain from their work due to their disease and become socially isolated. Poor exercise capacity has also been shown to contribute to mortality [7].

Pulmonary rehabilitation programmes aim at reversing this deleterious situation in terms of improvements in exercise capacity, activities of daily living, quality of life and perhaps survival. Pulmonary rehabilitation programmes must be comprehensive and flexible to address each patient's needs and include smoking cessation, optimal medical treatment, exercise training, breathing exercises, nutritional intervention, psychosocial support and health education [8]. Recently, well-designed studies investigated and confirmed the efficacy of pulmonary rehabilitation programmes [9]. As the impairment of exercise tolerance is a common problem in COPD patients, exercise training 
is considered an important component of the treatment. However, no consensus exists as to the best methods of exercise training [8]. No answers can be given to the question of which mechanisms contribute to improved exercise capacity. Adaptations in oxygen utilization and changes in fibre type distribution after training are still under research and will not be extensively discussed here.

In the present overview, we will discuss the contribution of exercise training and muscle training to the demonstrated effects of pulmonary rehabilitation programmes in clinical practice by means of six basic questions:

1) Is exercise training important in rehabilitation of COPD patients?

2) What is the optimal intensity for exercise training?

3) What training modalities should be prescribed?

4) Is it useful to combine exercise training with medication, nutrition or oxygen?

5) How should training effects be maintained?

6) Where should the rehabilitation programme be performed: in-patient, out-patient or homecare?

\section{Is exercise training important in rehabilitation of COPD patients?}

Recent randomized controlled studies reported significant improvements in maximal exercise capacity, walking distance and endurance capacity after pulmonary rehabilitation [10-14]. In addition, improved quality of life and reduced symptoms were observed [10, 11, 13, 15]. Mortality rate tended to decrease after rehabilitation [11]. Although conclusive evidence is not yet available, two additional observations support the potential importance of rehabilitation to survival. The intermittent positive pressure breathing (IPPB) trial demonstrated that exercise capacity is an independent contributor to mortality, independent of the degree of airflow obstruction [16]. In addition, a higher mortality rate was observed in patients with severe muscle weakness due to steroid-induced myopathy [17].

Although these programmes are comprehensive, most of the authors considered exercise training as a mandatory part of the programme. However, since no placebocontrolled studies were available, the effective part of the programme was unknown. Toshima et al. [18] and more recently, RIES et al. [11], showed that a rehabilitation programme, including exercise training, resulted in significantly larger improvements in exercise capacity, symptoms and quality of life than an educational programme alone (fig. 1). This provides a better answer to the question why rehabilitation is effective. If exercise training is important in COPD patients, then the question becomes what kind of exercise and exercise intensity should be described [19].

\section{What is the optimal intensity for exercise training?}

Efficacy of exercise training is related to general principles of exercise physiology, e.g. training intensity, training specificity and reversibility [20]. In healthy subjects, training intensity is mostly targeted by means of the percentage of the maximal cardiac frequency $(60-90 \%$ of the predicted maximal cardiac frequency) or a percentage of the maximal oxygen uptake (50-80\% pred) achieved dur-

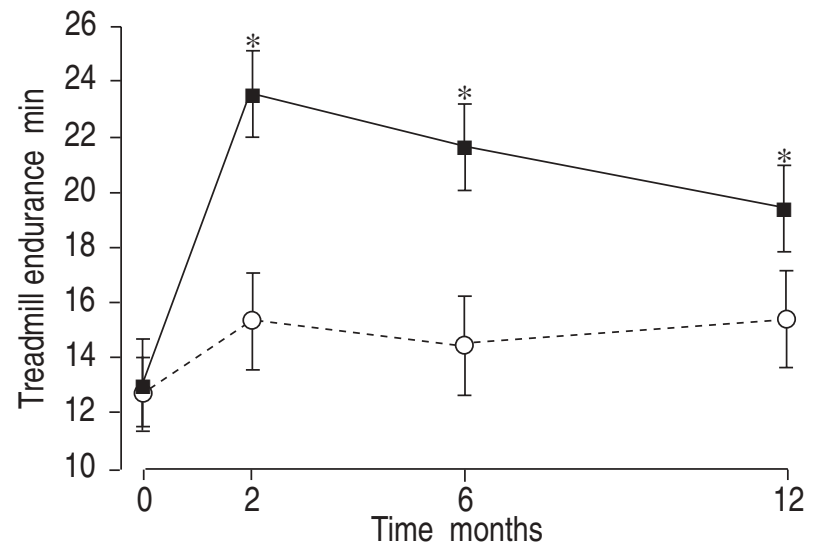

Fig. 1. - Rehabilitation results in significantly more improvement of exercise performance than an educational programme without exercise training. Results are mean $\pm \mathrm{SD}$. *: $\mathrm{p}<0.05$, versus control group. - - rehabilitation; .... . . : education. (From [11], with permission).

ing training. This intensity should be sustained for $20-45$ min, and repeated 3-5 times a week [20]. Training at this intensity is related to working conditions well above the anaerobic threshold, inducing anaerobic muscle metabolism. Exercise programmes based on these guidelines have been shown to increase maximal exercise performance, to produce adaptations in peripheral muscles and to improve cardiac function in healthy subjects [21].

The question whether these principles also apply to patients with COPD has only recently been addressed adequately. For many years, it was argued that work intensity during exercise training was too low in COPD to accomplish these adaptations in peripheral muscles. Data from Belman and KendREgan [22] were the main support for this statement, because the study failed to demonstrate changes in muscle enzymes after exercise training. However, it should be noted that their training programme had probably a low training intensity. Training intensity was defined as the highest tolerable training intensity that could be maintained for $20 \mathrm{~min}$. In the initial phase of the study, training intensity was only $35 \%$ of the maximal workload.

Notable progress concerning the training intensity in COPD patients was made by the work of CASABURI and coworkers [12, 23]. They showed that anaerobic metabolism was present during exercise in patients with COPD. Indeed, an early onset of lactic acidosis during exercise was demonstrated in these patients $[12,24,25]$. In addition, significantly larger improvements in maximal and submaximal exercise responses were obtained after exercise training at high exercise level $(70 \%$ maximal workload) above the anaerobic threshold (AT), compared to low exercise level (30\% maximal workload) [12]. They showed significant reductions in ventilation and lactate levels at identical submaximal workloads, strongly indicating improved aerobic metabolism. Reduced ventilation may be responsible for reduced dyspnoea at identical workloads after rehabilitation [13]. Recently, VALLET et al. [26] concluded that training with a training intensity targeted with the gas exchange threshold (GET) optimized training effects compared to training intensity targeted with cardiac frequency in COPD patients. Although these studies seem to promote the use of AT or GET as a training target, several comments may be made related to this 
practice. PunZaL et al. [27] observed significant improvements in exercise capacity after a symptom-limited, highintensity training programme. Surprisingly, their results were independent of whether or not the AT was reached during training.

The latter observation appears to contrast with the above-mentioned studies. However, the noninvasive detection of the AT used in the study by Punzal et al. [27] is still under debate and probably inaccurate, especially in patients with more severe airflow obstruction [24, 28]. In the study of Punzal et al. [27] the AT was detected with the noninvasive method. The patients who did not reach AT had more severe airflow obstruction. It is probable that anaerobic metabolism was present as observed in other studies $[24,25]$ in which lactate measurements in arterial blood were performed. Furthermore, MaLTAIS and co-workers $[14,29]$ showed that high-intensity training ( 60-75\% maximal workload) resulted in substantial in-creases in maximal exercise capacity and reductions in ventilation and lactate levels at identical exercise work rate. These findings strongly suggest improvements in aerobic metabolism and are in agreement with significant increases in oxidative enzymes (16-40\%) in the quadriceps femoris muscle after a strenuous exercise programme (70-80\% maximal workload) as found by the same group [14] (fig. 2). No such changes were found after low-intensity training [22].

Reductions in ventilation can also be attributed to mechanisms other than improved aerobic metabolism. CASABURI et al. [30] observed a significant reduction in deadspace ventilation due to a decrease in respiratory frequency and increase in tidal volume after exercise training in patients with severe COPD. This resulted in a lower minute ventilation despite an unchanged lactate level. These changes raise the question of additional breathing exercises during exercise training. CASCIARI et al. [31] observed significantly more improvement in maximal oxygen uptake after exercise training and breathing exercises compared to exercise training without breathing exercises. These findings suggest that breathing exercises during

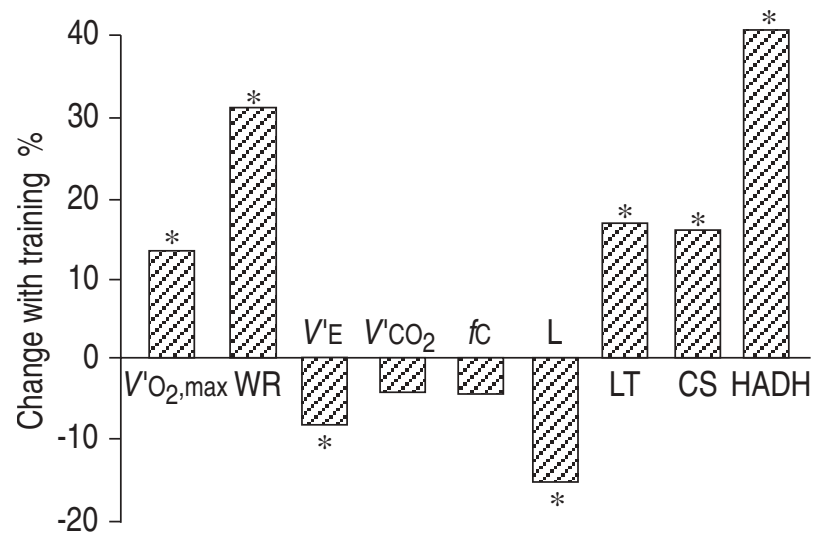

Fig. 2. - Changes in maximal exercise capacity (maximal oxygen consumption $\left(V^{\prime} \mathrm{O}_{2}, \max \right)$ and work rate $\left.(\mathrm{WR})\right)$, ventilation $\left(V^{\prime} \mathrm{E}\right)$, carbon dioxide output $\left(V^{\prime} \mathrm{CO}_{2}\right)$, cardiac frequency $(f \mathrm{C})$ and lactate $(\mathrm{L})$ at identical work load and lactate threshold (LT) after high-intensity training in patients with chronic obstructive pulmonary disease. Oxidative enzymes in the quadriceps muscle (citrate synthase (CS) and 3-hydroxyacyl CoA dehydrogenase (HADH)) increased significantly. *: $\mathrm{p}<0.05$, versus baseline. (From [14], with permission). exercise training can be beneficial. Further controlled studies are necessary to substantiate this.

The above-mentioned data strongly suggest that training intensity is significant, but the meaning of the level of lactate accumulation as training stimulus is still questionable [30]. This leaves us with the question of what is the ultimate stimulus for adaptations in trained muscles.

From a practical point of view, it is important to know how to evaluate training intensity during exercise training. The answer to this question is not readily given. Most studies suggest using a given percentage of the maximal work capacity. Cardiac frequency is also used as an easy measure to target training intensity. However, as work rate corresponding to a given cardiac frequency varies widely among subjects [32] and certainly changes due to lung disease [33] and drugs, cardiac frequency seems not to be an appropriate measure to target training intensity. Nevertheless, cardiac frequency changes at identical work load can be used to study cardiac adaptations in individuals after exercise training in COPD patients $[12,29,30]$. Recently, Horowitz et al. [34] observed that dyspnoea ratings (Borg-score) obtained from a maximal graded exercise test can be reliably used as a training target to produce specific exercise intensities during training over a 5 week period. This conclusion is supportive for symptom-guided exercise training. A proposal for targeting exercise intensity can be, for example, a Borg-score (either for dyspnoea or leg fatigue), as was used in several studies [11, 13, 27]. For safety reasons, in most training programmes transcutaneous oxygen desaturation $<85 \%$ is avoided by oxygen supplementation. This latter guideline, however, needs further investigation.

Most training programmes in COPD rehabilitation are based on endurance training, which practically means periods of sustained exercise for 20-30 min. However, in severely obstructed patients with hypoxaemia and hypercapnia, endurance training is very strenuous and exercise levels $>60 \%$ of the maximal workload are hardly tolerated for longer periods of time [14, 29]. Interval training, 2-3 min of high-intensity (60-80\% maximal exercise capacity) training alternated with equal periods of rest, seems an attractive alternative to train these patients. In healthy subjects, interval training has been shown to elicit similar training effects as endurance training [35-37]. Only one abstract has been published on the effects of interval training in severe COPD patients [38]. No differences were observed in the training responses compared to endurance training in patients with severe COPD, but with normal blood gases. Further research is warranted in this area.

\section{What training modalities should be prescribed?}

Training specificity implies that benefit is specifically gained in activities that were trained. This implies that the work during training should resemble conditions that are needed to be improved in COPD patients, i.e. activities of daily living. However, in clinical practice it is almost impossible to meet such conditions during exercise training. LAKE et al. [39] observed significant improvements in 6 min walking distance (6MWD) after lower extremity training, but not after upper extremity training. Similarly, upper extremity training improved arm ergometer performance, but not walking distance. Such specific training 
effects were also observed by others [11, 27]. Transfer effects to other activities have been shown, with cycle ergometer training improving walking $[15,40]$ and vice versa [10]. Transfer effects were also noticed as an increase in the activities of daily living or quality of life [41]. Concerning the specificity of training, studies considering the effects of occupational therapy are still lacking.

\section{Lower extremity training}

Most training programmes involve training of lower extremities with cycling or walking or both. The advantage of cycling is the accurate tuning of training intensity. However, only a few studies describe their training regimen in great detail $[12,14]$. According to the guidelines of the American College of Sports Medicine [20], training intensity should be $>60 \%$ of the maximal workload. As mentioned before, CASABURI et al. [12] showed that training on the cycle ergometer at $70-80 \%$ of the maxi-mal workload improved submaximal endurance time significantly more than training at $30 \%$ of the maximal workload (70 versus 9\%). Other studies applying cycle ergometer training at a workload of Š60\% of maximal workload showed similar improvements in maximal workload $(\sim 30 \%)$ and endurance time $[14,25,26]$. Similar improvements were observed in training programmes applying treadmill walking programmes $[10,11,27]$ or combined walking and cycling programmes [13]. The 6MWD improved by $10-25 \%[10,13]$. By way of contrast, WIJKSTRA et al. [15] trained their patients in a home- based programme at $60-75 \%$ of the maximal workload and improved maximal workload with only $10 \%$, while 6MWD increased only marginally $(2 \%)$. Their training programme was home-based and therefore supervision of the training sessions was likely to be less strict.

\section{Upper extremity training}

As patients with COPD report limitations for activities of daily living involving the upper extremities [42], several upper extremity training programmes were performed. RiEs et al. [43] observed only significant improvements in specific upper extremity performance tests after upper extremity training in comparison to a control group. However, these improvements did not result in significant changes in tests simulating activities of daily living. Specific training effects were also found by LAKE et al. [39]. Upper limb training improved arm ergometer tests, but not walking tests.

\section{Peripheral muscle training}

Recent papers [3, 4, 25] address the importance of weakness of peripheral muscle to the impairment of exercise capacity. Quadriceps force contributes significantly to 6MWD and maximal oxygen uptake [3, 4]. Another observation that points to the significance of muscle weakness in limiting exercise capacity is that, in spite of significant differences in lung function measurements, no significant differences were seen in post-transplant exercise capacity between single or double lung transplanta- tion [44]. This may partly be explained by the fact that peripheral muscle weakness or dysfunction plays an important role in exercise limitation in these patients [45]. Finally, MaltaIs et al. [25] observed significant reductions in oxidative capacity of the peripheral muscles in COPD patients.

To the best of our knowledge, only three studies investigated peripheral muscle training in COPD patients [41, 46, 47]. O'HARA et al. [47] studied the effectiveness of weight-lifting in addition to a programme with backpacking, in 14 patients, seven patients with dumb-bell weight-lifting and seven patients performing daily peripheral muscle training ( $\sim 60 \%$ one repetition maximum load). Although similar improvements in isometric muscle strength were observed in both groups, 12 min walking distance and exercise performance on a cycle ergometer test improved significantly in the training group only. Since between-groups statistical analysis was not included, no conclusion can be drawn from this study concerning additional effects of peripheral muscle training on exercise performance. Contrary to the former study, SIMPSON et al. [41] found in a randomized controlled trial that weight-lifting with loads ranging $50-85 \%$ of the one repetition maximum load resulted in significantly more increase in peripheral muscle performance than in the control group. In addition, improvements in quality of life, but not in exercise capacity, were found.

Along the same lines, CLARK et al. [46] performed a randomized controlled study to investigate the effects of a low (no additional loads) intensity leg and arm muscleconditioning programme. As could be expected, significant improvements in muscle endurance, but not in muscle strength, were observed. The endurance walk test and physiological adaptations at submaximal exercise (reduced ventilatory equivalents for oxygen and carbon dioxide) improved significantly in comparison to the control group. As in the study of SimpSon et al. [41], no changes in maximal exercise performance were present.

Preliminary data from our centre show that improvement in peripheral muscle strength and exercise performance are well correlated [48]. This finding further substantiates the causal relationship between peripheral muscle function and exercise capacity. It remains, however, unclear if either endurance muscle training, strength training or a combination of both is to be preferred.

\section{Respiratory muscle training}

Respiratory muscle function, and especially inspiratory muscle function, is compromised in COPD and this contributes to dyspnoea [49], exercise limitation [4] and hypercapnia [50]. Respiratory muscle training improves inspiratory muscle function on the condition that training intensity is fixed or monitored and exceeds $30 \%$ maximal inspiratory pressure $(P I, \max )$ [51-53]. This prerequisite was not considered in several studies previously published. Therefore, their results should be considered preliminary and interpreted with great caution. Inspiratory muscle training in addition to exercise training has been shown to result in greater improvements in exercise capacity in patients with a ventilatory limitation to exercise $[54,55]$. 
No data are available on which method of respiratory muscle training should be practised: resistive loading, threshold loading, maximal inspiratory (Müller) manoeuvres or a combination of these manoeuvres. Threshold loading has the advantage of being independent of inspiratory flow rate [56]. However, it requires build up of negative pressure before flow occurs, and hence, is inertive in nature. BELMAN et al. [57] showed that similar work loads were obtained during resistive loading and threshold loading. Whether resistive loading or this inertive loading produces different training effects, remains to be studied.

\section{Is it useful to combine exercise training with medica- tion, nutrition or oxygen?}

Whether or not to use supplemental oxygen therapy during exercise is still an unresolved question. Muscle function in COPD patients with long-term hypoxaemia has been shown to deteriorate $[25,58]$. Significant improvements in exercise performance [59] and muscular oxidative metabolism [58] are reported as acute effects of oxygen therapy in hypoxaemic COPD patients. Training with supplemental oxygen for 10 weeks had no additional effects over training without supplemental oxygen in COPD patients with exercise hypoxaemia [60]. By contrast, in healthy subjects, training under hypobaric conditions resulted in significantly larger increases in oxidative enzymes and endurance time compared to normobaric conditions [61]. This suggests that intermittent hypoxaemia could be an additional training stimulus. This contrasts to the traditional thoughts that supplemental oxygen is necessary to allow exercise at higher workloads in patients with severe airflow obstruction.

Nutritional interventions have been successful in gaining respiratory and peripheral muscle strength as well as improving exercise performance $[62,63]$ in malnourished COPD patients [63]. The additional effects of nutrition on exercise training have not been studied yet.

The administration of anabolic-androgenic steroids in combination with exercise training has only recently been shown to be effective in increasing muscle size and muscle strength in normal male subjects [64]. Although the concept seems attractive to comprehensive patient care, no studies are available at present in patients with COPD at present.

\section{How should training effects be maintained?}

The reversibility of training effects is well known [20]. These detraining effects were only mild in endurancetrained healthy subjects after stopping exercise training $[65,66]$. Recently, two studies were published discussing long-term effects of respiratory rehabilitation in COPD patients $[11,15]$. In the study of WIJKSTRA et al. [15], a 12 week exercise training programme was continued at two training frequencies on a low level basis (either once a week or once a month) after the initial training period. Apparently, there was a tendency for a decline in walking distance after 18 months, but surprisingly no significant differences were found between the two training frequencies. Patients included in the study of Ries et al. [11] also continued exercise training at home after a rehabilitation programme of 2 month duration. They visited the programme once a month, but the improvements in treadmill endurance capacity diminished after 12 and 18 months.

\section{Where should the rehabilitation programme be per- formed: in-patient, out-patient or homecare?}

Most rehabilitation programmes used in recent research are out-patient and hospital-based [11, 13, 14, 29, 30, 46]. GoLDSTEIN et al. [10] performed their programme on an inpatient basis for 2 months and thereafter another 4 months on an out-patient basis. Similar improvements were observed in this study compared to the out-patient programmes.

Homecare or community-based programmes were also studied [15, 40, 67]. In the study of Самвасн et al. [40], similar improvements were observed, on average, in walking distance and quality of life in community-based as in out-patient hospital-based programmes. However, only one third of the group were COPD patients and two thirds were asthmatics. Subgroup analysis revealed that COPD patients had only marginal improvements in walking distance after rehabilitation. STRIJOS et al. [67] reported similar improvements in exercise performance and dyspnoea after hospital-based and home-based rehabilitation compared to controls. Long-term effects on exercise capacity and dyspnoea were better maintained in the homecare group. However, such long-term benefit was not observed after a similar homecare programme studied by the same group [15]. Again in this study no significant improvement was observed in walking distance. In the study of CLARK et al. [46], patients followed a daily home-based programme that was supervised once a week in the hospital. Patients kept a record of their performance in a training log. This programme was associated with significant improvements in walking performance and ventilatory equivalents for oxygen and carbon dioxide. These findings suggest that an out-patient training programme and a home exercise programme can be successfully combined and must be considered in future research.

\section{Conclusions}

Is exercise training important in rehabilitation of COPD patients?

Exercise training has been proven to be an important part of respiratory rehabilitation programmes in COPD patients. Increased maximal exercise capacity and functional exercise performance were consistently observed after rehabilitation including exercise training.

\section{What is the optimal intensity for exercise training?}

As in training in healthy subjects, intensity of the exercise training programme is of key importance. Low-intensity exercise or muscle training in COPD patients resulted in modest improvements in submaximal exercise tests, but no increases in maximal exercise performance were observed. In contrast, high-intensity training improved both 
maximal and submaximal exercise tests and induced both cardiorespiratory and peripheral muscle adaptations, similar to those observed in healthy subjects. These studies have demonstrated that high-intensity exercise training is possible and safe in COPD patients, a conclusion that was held for unrealistic by previous reports.

\section{Which training modalities should be prescribed?}

As in healthy subjects, training effects are related to the training modality. Since training programmes in the literature were quite variable, detailed comparisons were not possible. Specific training effects were found after upper and lower extremity exercise training. However, most studies demonstrated transfer effects such as an increase in walking distance after training on a cycle ergometer. Training modalities should be chosen as near as possible to activities that are aimed to improve. In this perspective, introducing occupational therapy seems an important training modality. In addition, data are still lacking on the effectiveness of interval training in COPD.

Recently, peripheral muscle training has attracted interest. First, peripheral muscle weakness contributes to exercise limitation as shown in recent studies. Second, muscle training is a feasible training modality, particularly in patients with severe airflow obstruction. This type of training is possible without excess ventilation and therefore less dyspnoea. It is, however, unclear which muscle training regimen should be followed. As muscle strength was found to be related to physical performance, strength training seems appropriate. This was confirmed in recently obtained results, showing a correlation between improvement in muscle strength and exercise performance. However, low-intensity endurance muscle training seems also to be successful in improving exercise performance. Further research is warranted not only to discover which training regimen (strength or endurance) should be followed, but also which muscle groups should be trained. So far, most attention has been given to lower extremity muscle training, because lower extremity muscle weakness was observed. Data on upper extremity, neck and trunk muscle strength and training are also needed.

Respiratory muscle training has been shown to increase inspiratory muscle strength and exercise capacity in patients with inspiratory muscle weakness and a ventilatory limitation to exercise.

\section{Is it useful to combine exercise training with medication, nutrition or oxygen?}

Enhancing training effects with anabolic-androgenic drugs is an area of controversy. However, recent data from studies in male athletes, demonstrated significant improvements in muscle strength when weekly supraphysiological injections with testosterone were added to training. Similar experiments are needed in COPD patients. Nutrition has been shown to have an effect on muscle strength and exercise capacity, but no study has demonstrated additional effects of nutrition on exercise training. Supplemental oxygen during exercise training seems attractive because it allows higher training loads, without the risk of oxygen desaturation during training. The additional effects of oxygen have not been substantiated. It has even been argued that local acute hypoxia might be a stimulus for adaptations in the muscle. Further randomized controlled studies are needed to substantiate the use of oxygen therapy during exercise training.

\section{How should training effects be maintained?}

Given the reversibility of the training effects after cessation of the rehabilitation programme, follow-up programmes after the formal rehabilitation period must be provided. Optimal follow-up frequency of the sessions needs to be determined. Given that COPD patients frequently have exacerbations, short periods of rehabilitation over time may be necessary to prolong the effects of rehabilitation in the longterm.

\section{Where should the rehabilitation programme be performed: in-patient, out-patient or homecare?}

Out-patient-based programmes have shown significant improvements in exercise performance and quality of life. Expensive in-patient programmes therefore seem unnecessary. Walking distance did not improve in two homebased programmes. This could be attributed to a lower training intensity during the programme as a result of inadequate supervision. At this point in time, out-patientbased programmes show the best results and guarantee both the best supervision and a multidisciplinairy approach.

\section{References}

1. Wasserman K, Sue DY, Casaburi R, Moricca RB. Selection criteria for exercise training in pulmonary rehabilitation. Eur Respir J Suppl. 1989; 7: 604s-610s.

2. Grove A, Lipworth BJ, Reid P, et al. Effects of regular salmeterol on lung function and exercise capacity in patients with chronic obstructive pulmonary disease. Tho$\operatorname{rax} 1996$; 51: 689-693.

3. Hamilton N, Killian KJ, Summers E, Jones NL. Muscle strength, symptom intensity, and exercise capacity in patients with cardiorespiratory disorders. Am J Respir Crit Care Med 1995; 152: 2021-2031.

4. Gosselink R, Troosters T, Decramer M. Peripheral muscle weakness contributes to exercise limitation in COPD. Am J Respir Crit Care Med 1996; 153: 976-980.

5. Strauss MJ, Conrad D, Logerfo JP, Hudson LD, Bergner M. Cost and outcome of care for patients with chronic obstructive lung disease. Analysis by physician specialty. Medical Care 1986; 24: 915-924.

6. Decramer M, Gosselink R, Troosters T, Verschueren M, Evers G. Muscle weakness is related to utilization of health care resources in COPD patients. Eur Respir $J$ 1997; 10: 417-423.

7. Intermittent positive pressure breathing trial group. Intermittent positive pressure breathing therapy of chronic obstructive pulmonary disease. Ann Int Med 1983; 99 : 612-620.

8. Donner CF, Muir J, Rehabilitation and Chronic Care Scientific Group of the European Respiratory Society. Selection criteria and programmes for pulmonary rehabilitation in COPD patients. Eur Respir J 1997; 10: 744757. 
9. Lacasse Y, Wong E, Guyatt GH, King D, Cook DJ, Goldstein RS. Meta-analysis of respiratory rehabilitation in chronic obstructive pulmonary disease. Lancet 1996; 348: 1115-1119.

10. Goldstein RS, Gort EH, Stubbing D, Avendado MA, Guyatt GH. Randomised controlled trial of respiratory rehabilitation. Lancet 1994; 344: 1394-1397.

11. Ries AL, Kaplan RM, Limberg TM, Prewitt LM. Effects of pulmonary rehabilitation on physiologic and psychosocial outcomes in patients with chronic obstructive pulmonary disease. Ann Intern Med 1995; 122: 823832.

12. Casaburi R, Patessio A, Ioli F, Zanaboni S, Donner CF, Wasserman K. Reductions in exercise lactic acidosis and ventilation as a result of exercise training in patients with obstructive lung disease. Am Rev Respir Dis 1991; 143: 9-18.

13. O'Donnell DE, McGuire MA, Samis L, Webb KA. The impact of exercise reconditioning on breathlessness in severe chronic airflow limitation. Am J Respir Crit Care Med 1995; 152: 2005-2013.

14. Maltais F, Leblanc P, Simard C, et al. Skeletal muscle adaptation to endurance training in patients with chronic obstructive pulmonary disease. Am J Respir Crit Care Med 1996; 154: 442-447.

15. Wijkstra PJ, Van der Mark TW, Kraan J, Van Altena R, Koeter GH, Postma DS. Long- term effects of home rehabilitation on physical performance in chronic obstructive pulmonary disease. Am J Respir Crit Care Med 1996; 153: 1234-1241.

16. Anthonisen NR, Wright EC, Hodgkin JE, IPPB Trial Group. Prognosis in chronic obstructive pulmonary disease. Am Rev Respir Dis 1986; 133: 14-20.

17. Decramer M, de Bock V, Dom R. Functional and histologic picture of steroid-induced myopathy in chronic obstructive pulmonary disease. Am J Respir Crit Care Med 1996; 153: 1958-1964.

18. Toshima MT, Kaplan RM, Ries AL. Experimental evaluation of rehabilitation in chronic obstructive pulmonary disease: short term effects on exercise endurance and health status. Health Psychol 1990; 9: 237-252.

19. Fishman AP. NIH workshop summary. Pulmonary rehabilitation research. Am J Respir Crit Care Med 1994; 149: 825-833.

20. American College of Sports Medicine. Position stand. The recommended quantity and quality of exercise for developing and maintaining cardiorespiratory and muscular fitness in healthy adults. Med Sci Sports Exerc 1990; 22: 265-274.

21. Holloszy JO, Coyle EF. Adaptations of skeletal muscle to endurance exercise and their metabolic consequences. $J$ Appl Physiol 1984; 56: 831-838.

22. Belman MJ, Kendregan BA. Physical training fails to improve ventilatory muscle endurance in patients with chronic obstructive pulmonary disease. Chest 1982. 81: 440-443.

23. Casaburi R, Wasserman K, Patessio A, Loli F, Zanaboni $\mathrm{S}$, Donner CF. A new perspective in pulmonary rehabilitation: anaerobic threshold as a discriminant in training. Eur Respir J 1989; 2: 618s-623s.

24. Patessio A, Casaburi R, Carone M. Comparison of gas exchange, lactate, and lactic acidosis thresholds in patients with chronic obstructive pulmonary disease. Am Rev Respir Dis 1993; 148: 622-626.

25. Maltais F, Simard AA, Simard C, Jobin J, Despagnes P, Leblanc P. Oxidative capacity of the skeletal muscle and lactic acid kinetics during exercise in normal subjects and in patients with COPD. Am J Respir Crit Care Med 1996; 153: 228-293.

26. Vallet G, Ahmaidi S, Serres I, et al. Comparison of two training programmes in chronic airway limitation patients: standardized versus individualized protocols. Eur Respir J 1997; 10: 114-122.

27. Punzal PA, Ries AL, Kaplan RM, Prewitt LM. Maximum intensity exercise training in patients with chronic obstructive pulmonary disease. Chest 1991; 100: 618-623.

28. Gallagher CG. Exercise limitation and clinical exercise testing in chronic obstructive pulmonary disease. Clin Chest Med 1994; 15: 305-326.

29. Maltais F, Leblanc P, Jobin J, et al. Intensity of training and physiologic adaptation in patients with chronic obstructive pulmonary disease. Am J Respir Crit Care Med 1997; 155: 555-561.

30. Casaburi R, Porszasz J, Burns MR, Chang RSY, Cooper CB. Physiologic benefits of exercise training in rehabilitation of patients with severe chronic obstructive pulmonary disease. Am J Respir Crit Care Med 1997; 155: 1541-1551.

31. Casciari RJ, Fairshter RD, Harrison A, Morrison JT, Blackburn C, Wilson AF. Effects of breathing retraining in patients with chronic obstructive pulmonary disease. Chest 1981; 79: 393-398.

32. Katch VL, Weltman A, Sady S. Validity of the relative percent concept for equating training intensity. Eur $J$ Appl Physiol 1978; 39: 219-226.

33. Wasserman K, Hansen JE, Sue DY, Whipp BJ, Casaburi R. Principles of exercise testing and interpretation. 2nd Edn. Philadelphia, Lea \& Febiger, 1994.

34. Horowitz MB, Littenberg B, Mahler DA. Dyspnea ratings for prescribing exercise intensity in patients with COPD. Chest 1996; 109: 1169-1175.

35. Gorostiaga EM, Walter CB, Foster C, Hickson RC. Uniqueness of interval and continuous training at the same maintained exercise intensity. Eur J Appl Physiol 1991; 63: 101-107.

36. Poole DC, Gaesser GA. Response of ventilatory and lactate thresholds to continuous and interval training. J Appl Physiol 1985; 58: 1115-1121.

37. DeBusk RF, Stenestrand U, Sheehan M, Haskell WL. Training effects of long versus short bouts of exercise in healthy subjects. Am J Cardiol 1990; 65: 1010-1013.

38. Schols AMWJ, Coppoolse R, Akkermans M, Janssen PP, Mostert R, Wouters EFM. Physiological effects of interval versus endurance training in patients with severe COPD. Am J Respir Crit Care Med 1996; 153: A127.

39. Lake FR, Henderson K, Briffa T, Openshaw J, Musk AW. Upper-limb and lower-limb exercise training in patients with chronic airflow obstruction. Chest 1990; 97: 10771082.

40. Cambach W, Chadwick-Straver RVM, Wagenaar RC, Van Keimpema ARJ, Kemper HCG. The effects of a community-based pulmonary rehabilitation programme on exercise tolerance and quality of life: a randomized controlled trial. Eur Respir J 1997; 10: 104-113.

41. Simpson K, Killian KJ, McCartney N, Stubbing DG, Jones NL. Randomised controlled trial of weightlifting exercise in patients with chronic airflow limitation. Tho$\operatorname{rax} 1992$; 47: 70-75.

42. Tangri S, Woolf CR. The breathing pattern in chronic obstructive lung disease during performance of some common daily activities. Chest 1973; 63: 126-127.

43. Ries AL, Ellis B, Hawkins RW. Upper extremity exercise training in chronic obstructive pulmonary disease. Chest 1988; 93: 688-692. 
44. Low DE, Trulock EP, Kaiser LR, et al. Morbidity, mortality, and early results of single versus bilateral lung transplantation for emphysema. J Thorac Cardiovasc Surg 1992; 103: 1119-1126.

45. Evans AB, Al-Himyary AJ, Hrovat MI, et al. Abnormal skeletal muscle oxidative capacity after lung transplantation by 31 P-MRS. Am J Respir Crit Care Med 1997; 155: 615-621.

46. Clark CJ, Cochrane JE, Mackay E. Low intensity peripheral muscle conditioning improves exercise tolerance and breathlessness in COPD. Eur Respir J 1996; 9: 25902596.

47. O'Hara WJ, Lasachuk KE, Matheson PC, Renahan MC, Schlotter DG, Lilker ES. Weight training and backpacking in chronic obstructive pulmonary disease. Respir Care 1984; 29: 1202-1210.

48. Troosters T, Gosselink R, Rollier H, Decramer M. Change in lower limb muscle strength contributes to altered six minute walking distance in COPD. Eur Respir $J$ 1996; 9: 144s

49. Killian KJ, Jones NL. Respiratory muscles and dyspnea. Clin Chest Med 1988; 9: 237-248.

50. Begin P, Grassino A. Inspiratory muscle dysfunction and chronic hypercapnia in chronic obstructive pulmonary disease. Am Rev Respir Dis 1991; 143: 905-912.

51. Lisboa C, Munoz V, Beroiza T, Leiva A, Cruz E. Inspiratory muscle training in chronic airflow limitation: comparison of two different training loads with a threshold device. Eur Respir J 1994; 7: 1266-1274.

52. Belman MJ, Shadmehr R. Targeted resistive ventilatory muscle training in chronic pulmonary disease. J Appl Physiol 1988; 65: 2726-2735.

53. Heijdra YF, Dekhuijzen PNR, van Herwaarden CLA, Folgering HTM. Nocturnal saturation improves by target-flow inspiratory muscle training in patients with COPD. Am J Respir Crit Care Med 1996; 153: 260-265.

54. Wanke T, Formanek D, Lahrmann H, et al. The effects of combined inspiratory muscle and cycle ergometer training on exercise performance in patients with COPD. Eur Respir J 1994; 7: 2205-2211.

55. Dekhuijzen PNR, Folgering HTM, van Herwaarden CLA. Target-flow inspiratory muscle training during pulmonary rehabilitation in patients with COPD. Chest 1991; 99: 128-133.
56. Gosselink R, Wagenaar RC, Decramer M. The reliability of a commercially available threshold loading device. Thorax 1996; 51: 601-605.

57. Belman MJ, Warren CB, Nathan SD, Chon KH. Ventilatory load characteristics during ventilatory muscle training. Am J Respir Crit Care Med 1994; 149: 925-929.

58. Payen J, Wuyam B, Levy P, et al. Muscular metabolism during oxygen supplementation in patients with chronic hypoxemia. Am Rev Respir Dis 1993; 147: 592-598.

59. McDonald CF, Blyth CM, Lazarus MD, Marschner I, Barter CE. Exertional oxygen of limited benefit in patients with chronic obstructive disease and mild hypoxemia. Am J Respir Crit Care Med 1995; 152: 1616-1619.

60. Rooyackers JM, Dekhuijzen PNR, van Herwaarden CLA, Folgering HTM. Training with supplemental oxygen in patients with COPD and hypoxaemia at peak exercise. Eur Respir J 1997; 10: 1278-1284.

61. Terrados N, Jansson E, Sylven C, Kaijser L. Is hypoxia a stimulus for synthesis of oxidative enzymes and myoglobin? J Appl Physiol 1990; 68: 2369-2372.

62. Wilson DO, Rogers RM, Sanders MH, Pennock BE, Reilly JJ. Nutritional intervention in malnourished patients with emphysema. Am Rev Respir Dis 1986; 134: 672-677.

63. Rogers RM, Donahoe M, Costantino J. Physiologic effects of oral supplemental feeding in malnourished patients with chronic obstructive pulmonary disease. A randomized control study. Am Rev Respir Dis 1992; 146: 1511-1517.

64. Bhasin S, Storer TW, Berman N, et al. The effects of supraphysiologic doses of testosterone on muscle size and strength in normal men. N Engl J Med 1996; 335: 1-7.

65. Coyle EF, Martin WH, Sinacore DR, Joyner MJ, Hagberg JM, Holloszy JO. Time course of loss of adaptations after stopping prolonged intense endurance training. J Appl Physiol 1984; 57: 1857-1864.

66. Coyle EF, Martin WH, Bloomfield SA, Lowry OH, Holloszy JO. Effects of detraining on responses to submaximal exercise. J Appl Physiol 1985; 59: 853-859.

67. Strijbos JH, Postma DS, Van Altena R, Gimeno F, Koeter GH. A comparison between outpatient hospital-based pulmonary rehabilitation program and a home-care pulmonary rehabilitation program in patients with COPD. A follow-up of 18 months. Chest 1996; 109: 366-372. 